\title{
Cloud Computing Data Center Adoption Factors Validity By Fuzzy AHP
}

\author{
Nasrin Badie \\ Department of Information System, Faculty of Computing, University Technology of Malaysia, 81300 Skudai, \\ Johor Bahru, Malaysia \\ Email:nasrin.badie@gmail.com
}

\author{
Ab Razak Che Hussin \\ Department of Information System, Faculty of Computing, University Technology of Malaysia, 81300 Skudai, \\ Johor Bahru, Malaysia \\ Email:abrazak@utm.my \\ Arash Habibi Lashkari \\ Department of computer Science, Faculty of Computing, University Technology of Malaysia, 81300 Skudai, \\ Johor Bahru, Malaysia \\ Email:ahabibill@hotmail.com
}

Received 31 March 2014

Accepted 18 June 2015

\begin{abstract}
Most sectors of the economy like the universities, high-tech, financial services, and government institutions have data center. However, there are some issues which encompass current data center such as physical location, energy consumption, performance, flexibility. Big organizations like Google, IBM have migrated toward cloud computing, and using cloud data center as the most cost efficient alternative to the current data center. Cloud computing is a model that provides suitable and on-demand access to a shared pool of configurable computing resources, but unfortunately, it has some attendant problems like security issue, lack of proper policy and standardization. Therefore, in spite of the provision of all the benefits of cloud computing, such as cost reduction, flexibility, easy implementation and accessibility, some organisations are suspected to move toward cloud computing data center. Therefore, the main focus of this paper is to determine the critical success factors for the adoption of cloud computing data center. To achieve this, a structural literature review of existing work and semi structured interview with ten IT administration and IT staff were carried out. We also performed a content validity using a panel of experts including 12 experts with more than 5 years experience. Subsequently, a FAHP technique was used to evaluate experts' consensuses.
\end{abstract}

Keywords: Cloud Computing, Data Center, Adoption Model, Fuzzy AHP, Success Factors, 


\section{Introduction}

Cloud computing has been an emerging research topic since the late of 2007 due to its abilities to offer flexible and dynamic IT infrastructures, quality of service (QoS) guaranteed computing environments and configurable software services. ${ }^{1}$ Generally, cloud computing is a business purpose into forming the field network revolution, it is an extension and development of parallel computing, distributed computing, and grid computing.

Moreover, cloud increased many new features, the data center concept is scattered through the high-speed network interconnection. Through the resource integration of virtual into pool way, to offer a way for users of the WEB, Users request a calculation, data center according to the task of segmentation and assigned suitable child nodes running, and the results of the calculation results are formed together and then returned to the user.

Cloud computing has numerous benefits including cost reduction on infrastructure and implementation. Provision of services by the data center amounts to one of the significant benefits of cloud computing. ${ }^{2-4}$ In consideration of the problems associated with the current data center such as energy consumption, physical location, non-flexibility of supporting the variety of network services and applications (e.g. video streaming), the result of which have support for quality of service, deployability, manageability, and defence against security attacks, and also poor server utilization and high operational cost . $^{5}$ Neither performance isolation nor failure can restrict the communication pattern and bandwidth usage of each application, which causes vulnerability to insider attacks such as performance interference and Denial of Service (DoS) attacks, and difficulty in introducing changes in traditional data center networks.${ }^{5-7}$ The data centers needed for Cloud Computing is mounting exponentially. ${ }^{8}$

Pay-as-you-go access to cloud based services are made it as a cheaper substitute to traditional data centers, since clouds often provide on-demand services and data center network virtualization, an expectant solution to address problems relating to the performance, flexibility, lower cost, scalability, better resource utilization, and energy efficiency. 9,10

Nowadays, big companies like Amazon, Google, Face book, and Yahoo regularly use data center for storage, Web search, and large-scale computations. With the emergence of cloud computing service, hosting in data centers has been a huge investment that plays very important role in the future of Information Technology (IT) industry.

Furthermore, small-scale IT operations are likely to become consumers of cloud services . ${ }^{11}$ Majorities of these companies have in-built services that utilise cloud computing to forecast the market, tailor pricing and optimize their procurement and manufacturing. Also, these companies have instantiated different Internet consumer services such as social networking, email and Internet, that utilize the services of cloud computing. However, aside this various benefits of cloud computing data center, some organizations are uncertain about migrating towards the cloud based data center concerning some problems such as security issue . ${ }^{12}$

\section{Related Works Current Models Review}

The objective of this paper, however, is to evaluate cloud-based data center adoption factors. Some models, mentioned in this paper, which are chosen as samples amongst some existing models evaluated in a very important organization. The study of these models and the review of related literature revealed that there are some factors that are not considered by the existing models. This study therefore, is aimed at proposing a conceptual model, based on the ignorant factors, and evaluates it to solve the problems associated with the adoption of cloud computing by universities.

\subsection{Cloud Computing Data Center Adoption Model (CCDCAM)}

However, finding critical success factors that leads to adaption of cloud-based data center is the major objective of this paper. These factors are mixed of new and existing factors which influence interest of IT decision maker for adoption of cloud computing data center.

- Security: Security is unequivocally one of the main issues for Cloud computing adoption and indeed is frequently cited as one of its key obstacles. The level to which security may become a hindrance is dependent on the nature of the service an organization is planning to offer in the Cloud, the model of Cloud the service is to be deployed and the level of security policy development of an organization. ${ }^{13}$

- Performance: The communication time between the client computer and the Web server in the cloud has been the major source of performance 
problem for cloud services. This problem becomes more intense as the number of concurrent users rises, and the volume of data transferred to and from the cloud rises. What also makes a different is the physical distance between the client computer and the cloud. ${ }^{14}$

- Compliance: Enterprises are subject to many government regulations relating to storage security, privacy, and disclosure of data in the United States. The regulations encompass Sarbanes-Oxley Act for corporate accounting data and Health Insurance Portability and Accountability Act (HIPAA) for healthcare insurance data of Americans. Cloud computing was not taking into consideration while the regulations were written. Cloud computing is an enterprise storing data on a third-party computing facilities that are shared with other enterprises. However cloud computing, need to be more fit with the related regulation. ${ }^{14}$

- Environment: An article was published recently in the economist, which pointed out that the computers in the clouds have been consuming megawatts of power at an ever-increasing rate, despite the fact that some are not built to the best energy-efficiency standards. Consequently, the movement of data center operations from corporations' premises to the clouds is not reducing the global power $\mathrm{c}^{\text {ons }}$ umption or the carbon-dioxide (CO2) emission. The commitment of the infrastructure service providers to increasing energy sufficiency in data center operations should be enforced ${ }^{14}$

\subsection{Decision Support Model for Adopting Cloud Computing (DSMACC)}

The compilation of the standardization within the Track (SWiFT) process has been made and it serves as a guide for the incorporation of all Cloud delivery and deployment models. Therefore, the suitability of Cloud adoption is assessed based on the guide, which should be used in compliance with the available models for more thorough analysis.

- Context: The first phase in this guide is the evaluation of why Cloud Computing is being proposed for the organization and its effect. ${ }^{14}$

- Nature of deployment: The second phase is to have a deep thought about the nature of the service or application under concern for cloud adoption and its suitability for the cloud model. ${ }^{16}$

- System availability: Since the model by which cloud computing services are deployed is modified by Cloud computing, it becomes important to ponder and understand both the positive and negative impacts Cloud computing will have on the availability of the system. The gravity of this effect will vary depending on the business criticality of the application or service being considered for the deployment Cloud computing. ${ }^{15}$

- $\quad$ Privacy and protection: The comprehensive nature of cloud computing has been one of its major advantages. However, exporting personal data outside the European economic area is seriously synchronized. There is need for any organization willing to adopt Cloud computing to be fully knowledgeable of its obligations under all applicable data protection law and be sure that all necessary safeguards are in place.$^{15}$

- Network Infrastructure: Model based on cloud computing network infrastructure provides vital internet access, ascertaining the correct size, as well as having good reliability and adequately built redundancy critical to the successful deployment of cloud..$^{15}$

- Flexibility: Cloud computing offers operation flexibility, which is one of its major advantages. ${ }^{15}$

- Data storage and extraction: The primary benefits of most organizations are data and hence it is vital to know how the proposed cloud model will manage the data. Consideration should be given to data custody, backup, expansion and extraction and the data should be planned for in advance.$^{15}$

- Capacity planning: Estimated development of the application or service should be considered as well as the degree to which it supports or affects a Cloud adoption model.$^{15}$

- Customizations: If any, the needed level of customization should be considered and also determine the degree to which it favors or affect a Cloud adoption model. Many new vendors are yet to fully embrace the adoption of Cloud computing. It is significant to understand the maturity and adoption speed of any Cloud vendor or application or service being considered.$^{15}$ 
- Contingency planning: In a situation in which all systems control is handed over to $\mathrm{s}$ Cloud provider, contingency planning is a serious issue. The available contingency planning and the failure of responsibility for its provision should be understood.

- Outage: The death of a Cloud service provider results in permanent outage. This phenomenon has occurred in the past, and it is bound to happen again. Momentary outage of cloud computing services is possible and it is likely to happen several times a year, which may last a few hours or nearly one full day or even longer each time it occurs. ${ }^{14,15}$

- Internal skill-sets and governance: The impact Cloud computing on the IT department needs to be forecast by organization and the consideration of Job roles, processes and governance model implications when adopting the Cloud is required 15

- Commercial considerations: The knowledge of the overall cost rather than the deadline figure is important for the consideration of commercial concept of adopting Cloud computing. The detail assessment and knowledge of commercial implications of the adoption of Cloud computing are not compulsory. ${ }^{15}$

- Cost: Generally, cost is an issue in the consideration of adoption of Cloud computing. People go for "only pay for what you use" part of the marketing definition of cloud computing as a given. In the 1980s and 1990s, people trivialized the promise of cost savings in outsourcing software development from the US or Japan to countries such as India, China, etc. Despite the significance of cost savings, it turned out to be much less than it had been presumed because of the need to communicate between the two parties (e.g., travel, stationing staff), to re-do work that was not done properly, gradual increase in fees charged, etc. ${ }^{14,15}$

- Integration: Organizations are required to integrate applications and data on multiple public clouds, since they adopt several service providers. Furthermore, the organizations are required to integrate application and data between the private clouds and the public clouds. ${ }^{16,17}$
- Technologies like enterprise information integration (or federated database systems), enterprise application integration, and enterprise service bus can be customised to address the cloud 14

- Cloud contracts: Cloud computing encompasses the remote requirement of computing service, which is a commercial agreement between a supplier and a customer based on contract. The relationship between the parties and is of central importance to any Cloud computing deal or project is controlled by the Cloud contract. ${ }^{15}$

\subsection{IBM Framework for Cloud Adoption (IFCA)}

The interest of enterprises in the adoption of cloud computing increases with its various advantages spanning elastic scaling, faster service provisioning, greater IT efficiencies and usage-based accounting. It is difficult, if not impossible, for organizations to have a strong discussion on cloud computing without a common terminology and a standardized frame of reference within the company, between IT and business leaders, or among the professionals within the IT organization. This has obscured the development of a successful enterprise adopting strategy for cloud computing. ${ }^{18}$

- Standardization: With the various widely discussed advantages of cloud computing, including elastic scaling, faster service provisioning, greater IT efficiencies and usage-based accounting, enterprises are increasingly interested in the adopting of a cloud computing environment. Without a common terminology and a standardized frame reference, it is difficult, if not impossible, for organizations to have a strong discussion on cloud computing - externally with service providers, within the company, between IT and business leaders, or among the professionals within the IT organization. This alone has created an obstacle to developing a successful enterprise adoption strategy for cloud computing. 
A cloud computing adoption framework that establishes common definitions for the delivery model and services for cloud computing has been developed by IBW in order to address issue of cloud standardization

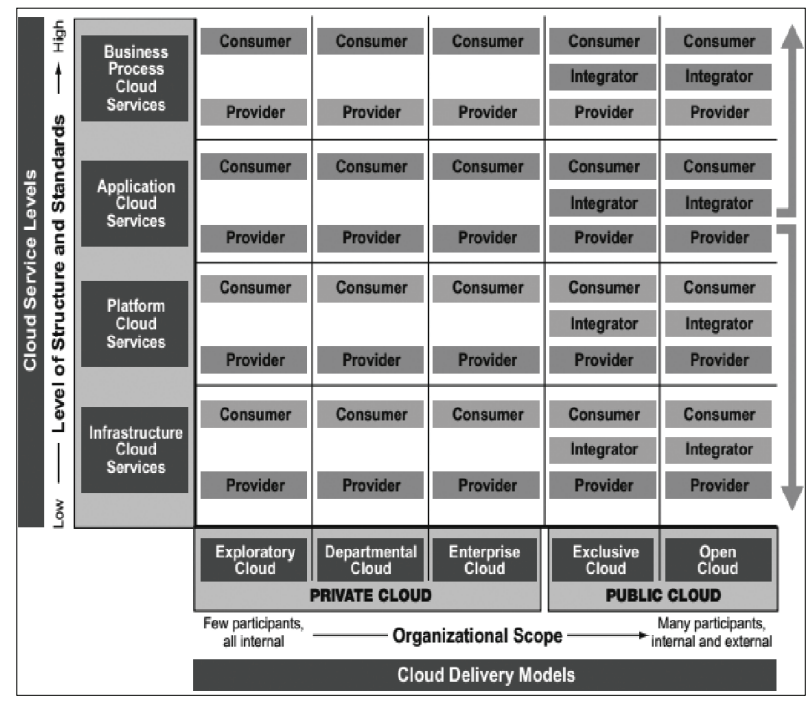

Fig.1. Cloud subtypes. (Source: 18)

The cloud computing adoption framework defines the levels of responsibility for the consumer, provider and integrator roles in the private and public cloud models which Figure 2 illustrates it.

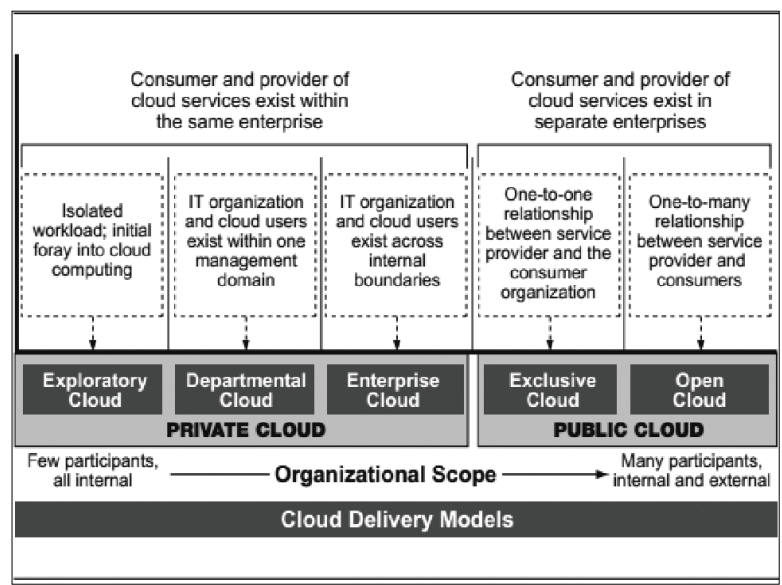

Fig.2. Roles and responsibilities (source: 18,19).

\subsection{Cloud Computing Adoption Tool-Kit Conceptual (CCATC)}

The challenges the decision makers are facing while assessing the feasibility of the adoption of cloud computing in their organizations and the Cloud
Adoption Toolkit developed to support this process are discussed in this research. The toolkit made provision for a framework to support decision makers in recognizing their concerns, and matching these concerns to the proper tools/techniques that can be used to address them Figure 3 demonstrates Cloud Computing Adoption Tool-Kit Conceptual (CCATC). ${ }^{19}$

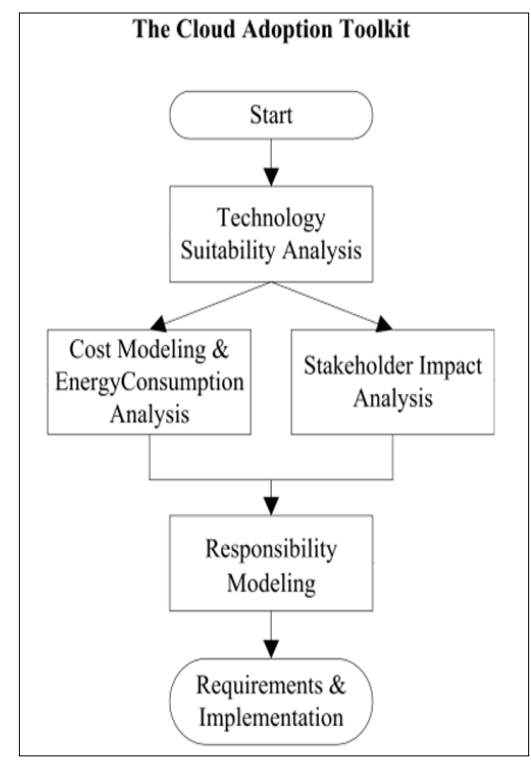

Fig.3. Cloud adoption conceptual framework (source: 19)

- Technology Suitability Analysis: The significance of Technology Suitability Analysis is to support decision makers in determining whether cloud computing is the suitable technology to support their proposed system. It is imperative to have knowledge of the characteristics of cloud computing as it has the potential to exhibit drastically different properties to those of conventional enterprise data centers.

- This is majorly as a result of the high scalability of cloud; physical resource sharing between virtual machines, developed to support this process is discussed in this research. The toolkit made provision for a framework to support decision makers in recognizing their concerns, and matching these concerns to the proper tools/techniques that can be used to address them.

- Cost Modeling: It supports the modeling of the costs of running a server infrastructure on the 
cloud. Cost modeling therefore supports cloud adoption decisions in two ways:

(i) It assists the decision makers in the acquisition of accurate cost estimates of running IT systems on the cloud.

(ii) It helps the system architects in the evaluation of the design of a proposed IT system with respect to its operational costs and gives them the privilege to compare the costs of various options.

\subsection{Conceptual Model for Adoption of Cloud Computing (CMACC)}

Figure 4 shows Conceptual Model for Adoption of Cloud Computing (CMACC). The purpose for the proposed of this Conceptual Model is to conduct an investigation on the factors that affect the adoption of cloud computing by organization categorized as hightech industry. The eight factors examined in this study have relative advantage, complexity, competitive pressure, Top Management Support, compatibility, firm size, technology readiness, and trading partner pressure $^{20}$.

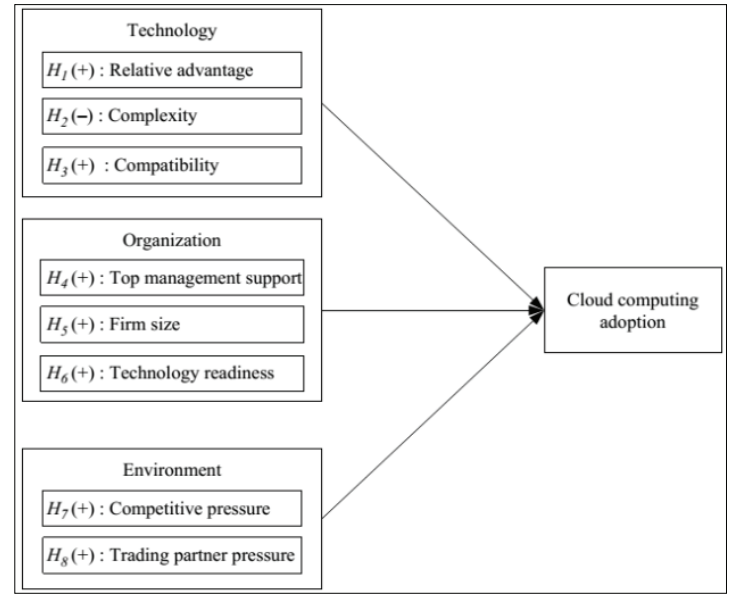

Fig.4. Conceptual Model for adoption of Cloud computing (source: ${ }^{20}$ )

- Relative advantage and complexity. Rogers ${ }^{21}$ defined relative advantage as the extent to which people perceive a technological factor as providing greater benefit for firms.
- Compatibility. Compatibility refers to the extent to which innovation fits with the existing values of potential adopter, previous practices and current needs . ${ }^{21}$

- Competitive and trading partner pressure: Competitive pressure refers to the level of pressure felt by the firm from competitors within the industry. . $^{23,22}$

- Top Management Support and firm size: The organizational context includes attributes like Size of the organization, Quality of human resources, how complex the firm's managerial structure is. $^{24,23}$

- Technological readiness: The technological readiness of organizations, implies technological infrastructure, IT and human resources. ${ }^{22-26}$

\subsection{Cloud Computing Adoption Model (CCAM)}

The overall effect of cloud computing investment announcements on the positive abnormal returns of shareholders is theoretically incorporated in the research on Cloud Computing Adoption Model (CCAM). ${ }^{28}$

The study is also charged with the recognition of the situations under and environmental aspects. The firm size, industry sector, and strategic intention are also implemented in the research model to investigate their moderating effects on the market value of the firm. Frequently the firm's size and the industry sector considered as significant moderators in event of work study ${ }^{27}$. Also charged with the recognition of the situations under which the influence of cloud computing investment can be changed. These conditions can be conceptualized as contextual factors 


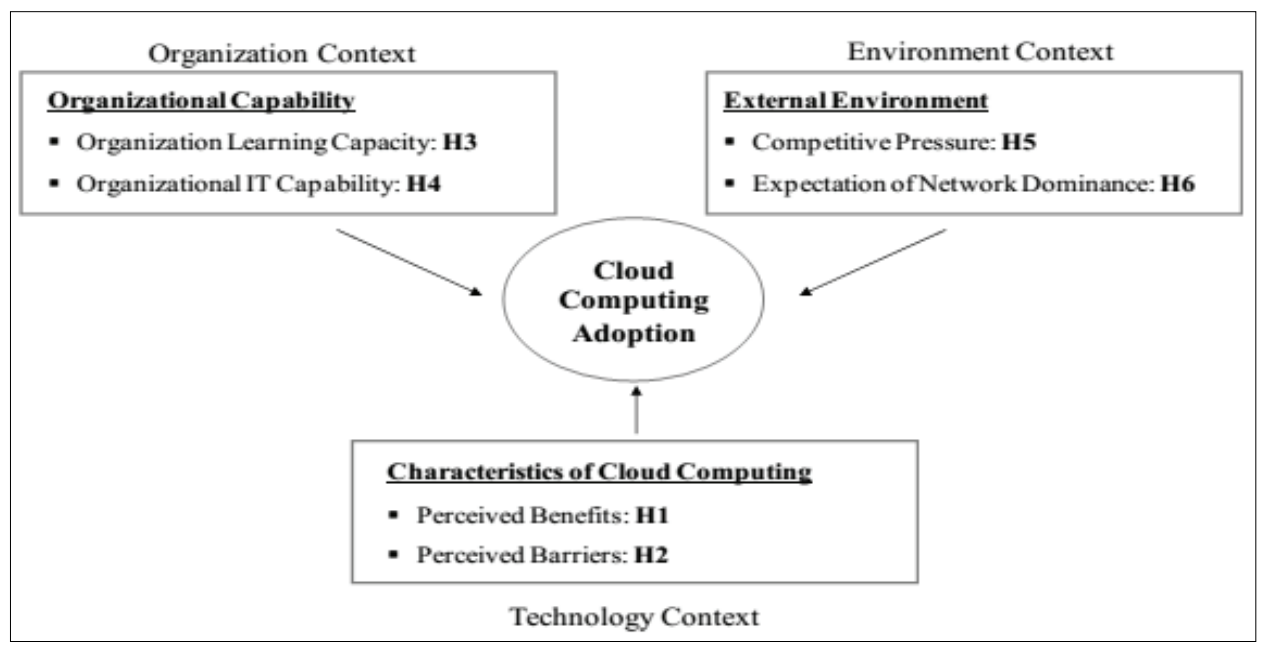

Fig.5. Cloud Computing Adoption Model (source: 28, see attachment)

that represent the firm's organizational.$^{28}$ Figure 5 shows this model.

- Characteristics of Cloud Computing (Technology Context) Concrete analysis for reliable decisionmaking references based on the relative amount of total expected benefits earned from and total costs paid for adopting the new technology is required for new technology innovation.$^{29}$ On this note, the adoption of cloud computing usually is dependent on the relative size of costs and the estimated benefits while the expected costs and benefits regarding a specific technology innovation are usually credited to its original features.${ }^{30}$ Hence, the technology context of the research model is represented by the perceived benefits and the barriers . ${ }^{28}$

- Organizational Capability (Organization Context): The ability of an organization to acknowledge new technological innovations and use them to promote its business competence is termed organizational capability. This capability can be attained on the basis of the organization's skill, knowledge, experience, etc. The perspective of organizational capability comprises two parts: organizational learning capability 31 and organizational IT capability .32

- External Environment (Environment Context). The decision making of a firm as regards adopting the available technology innovations in the market is affected by the significant role played by its external environment. ${ }^{33}$ The strategic IT solution to achieving a firm's business competence by improving its IT zealousness, business IT alignment, and IT cost-effectiveness is attributed to cloud computing. Factors such as competitive pressure, expectation of network dominance that instantiates from bandwagon effect ${ }^{29}$ and herding behavior,$^{34}$ can be useful for the prediction of variance of organizational intention to adopt cloud computing . ${ }^{20}$

\section{Critical Success Factors}

The factors that stimulate the adoption of cloud computing by enterprise, industries and organization have been examined by a few studies. Figure 6 contains the summary of the factors influencing the adoption of cloud computing by various organizations as found in the reviewed literature. ${ }^{14,19,20,35-38 .}$

Figure 6 categorized the factors affecting cloud computing into three main classes based on the latest models and existing theories: Technology, organization, and environment.

- Technology is include the technical factor that influences the adoption of cloud by organizations such as Relative Advantage that investigate about the advantage which new technology bring for 
organization, the Complexity of this technology and the Compatibility and customization of this technology by the strategies of the organization and existing infrastructure of its.

- The organizational latent introduces the factors which differentiate organizations from each other, such as Top Management Support, Firm Size and infrastructure, and Policy and Standardization. Another latent here was environmental factors such as Competitive Pressure, and Trading Partner Pressure which implies the importance of the adoption of technology by a competitor and partner influence in the adoption of new technology. Some factors because of their definition come under more than one category. Each construct has between three to more indicators which show in table under them. In the next step the validity of these factors is examined.

- In this study Outage and Security can come under both technical and organizational latent. Only by doing a real survey, we can find their real place. In the next step of this study we are going to do some analysis and survey to recognized the real place of factors which are categorized under two or more categories.

During this study one new category termed general factor is finding which used by a few studies and the researcher add it to the model to later evaluate its importance. The new items base on the definition that is considered by research is divided between main construct and the other items assigned as their indicator. In this study the construct are Relative advantage, Complexity, Compatibility, Top Management Support, Firm size Customization, Policy and Standardization, Competitive pressure, Trading partner pressure Number of Establishments, Number of Employees ,Outage, and Security. Each one of this construct has between three to more indicators which show in table under them. In the next step the validity of these factors is examined.

\section{METHODOLOGY}

\subsection{Content Validity test}

Numerous definitions of content validity have been published.$^{39-46}$ The applicability of content validity for all assessment methods is reflected by the assessment instrument. This validity is a cohesive assessment judgement of the extent to which experimental evidence and theoretical justifications support the sufficiency and suitability of interpretations and actions based on test scores or other modes of evaluation. In the recurrent form of validity, it is based on expert judgments about the significance of the test content to the content of a particular behavioural domain of interest and about the representativeness with which item or task content covers that domain.

For instance, the items in clerical job selection assessment relative to the properties of the available job and the highlighted job functions in the just analysis couple with the items in a personality assessment relative to the behaviours and applicable implied in a particular trait theory. Thus, the heart of the view of so-called content validity is that the test items are samples of a behavioural domain or item universe about which inferences are to be drawn or predictions made.

In this study, beside the literature review and in purpose of finding new factors for adoption of cloud computing data center interview was conducted with the administrators, and IT staff of center of information and communication technology of Universities in Malaysia. Through the interview and coupled with the reviewed literature, 13 construct related to Cloud Computing Data center Adoption (CCDCA) were obtained. These constructs are relative advantage, complexity, compatibility, security, outage, firm size, Top Management Support, customization, general factors include number of establishments and number of employees, competitive pressure, policy and standardization, and trading partner pressure. For each construct some subconstructs introduced as measurement of it.

However, after digging literature more deeply it has been found that compatibility and customization are same factors in definition and items used for measuring them, ${ }^{15,58,62,63}$ as well as firm size and general factor. ${ }^{59,60,61,64}$ Validation of the content validity is carried out to assess the relevance of these factors to CCDCA. To achieve this, a panel of experts with more than 10 years experience in this area comprising local and overseas experts were chosen based on their outstanding profile. Fifty questionnaires were sent to them in two ways face to face and online.They were directors and deputy directors of Information and Technology Center (ICT) who have experience in cloud computing, data center, security, network, policy, programming, and hardware for more than 10 years. They are from UTM ,UM ,USM ,UKM ,UPM , UTeM ,UiTM ,MMU,UPSI,UMP universities and MYREN from Malaysia, university of Melbourne, Sydney, and QUT from Australia, and cloud 
computing policy expert from European Network and Information Security Agency (ENISA).

Also, the questionnaire sent to experts, designed based on 4-point Likert Scale respectively including essential, relevant, not relevant, and not essential.The factors selected by most of the experts are essential and relevant factors or in other words, as Critical Success Factors (CSF) which influence the adoption of cloud computing data center by organization based on the result of content validity while the that are irrelevant factors are expunged. For verification content validity is used. 52 Content cannot be validate statistically, it only validate by referring to experts and literature. Thus, for quantifying content validity one of the common and most widely used methods which called Content Validity Ratio(CRV) is chosen in this study. ${ }^{53}$ Specifically, CVR $=(\mathrm{Ne}-(\mathrm{N} / 2)) /(\mathrm{N} / 2)$ where $\mathrm{N}=$ total number of respondent and where ne is the number of expert who indicating that the item is "essential,". 54

In Table 1 the experts' answer for each question are shown (reffer to appendix). The factors that have CVR $\geq 0.75$ are accepted as essential factors. Almost all factors including Relative Advantage, Complexity, Compatibility, Security, Outage, Top Management Support, Standardization and policy, Competitive pressure, and firm size, were considered to be essencial in opinion of more than half of expert. It is worthwhile to note that the experts have no consensus regarding the trading partner pressure, firm size, and general factors. The percentage of essentiality for these factor were $50 \%, 16 \%, 16 \%$, and $33 \%$ respectively.

However, since by deleting trading partner pressure item, just one item (Competitive pressure) was remaining under the environment construct and more than half of expert chose it as essential factor; again the relevance of this item checks during the Fuzzy Analytic Hierarchical Process (FAHP) test. In the next step, to evaluate the consensus of experts about this result and to remove the fuzziness of human decision, a FAHP test is carried out.

\subsection{Fuzzy Analytic Hierarchical Process (FAHP)}

Figure 7 is about the framework of proposed evaluation criteria. A general theory of measurement which depends on the values and judgments of individuals and groups is termed Analytic Hierarchy Process (AHP). AHP has been widely applied to multi-criteria decision making, planning and re-source allocation, conflict resolution, and also prediction problems in numerous fields. Cloud Computing adoption is a multi criteria decision making problem.$^{47}$ The organization should consider many aspects including benefits, cost, opportunity, and risk because cloud computing is still in its developing and perfecting process.

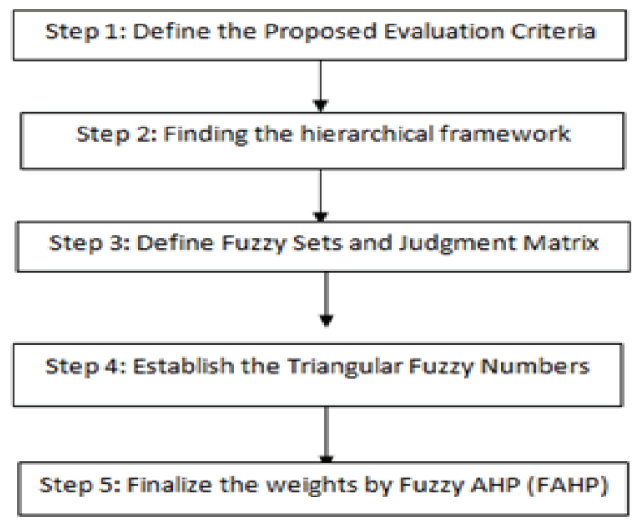

Fig.7. The Framework of proposed evaluation criteria

There are several of methodologies for decision making support, but the AHP emerges the most popular and prominent methodology due to its effectiveness and ease of use. ${ }^{48}$ However, since the human decision has fuzziness problem and uncertainty. In this paper, the FAHP is used .

\subsection{Fuzzy Logic and Fuzzy Set}

Fuzzy numbers are the distinct classes of the fuzzy quantities and it is a fuzzy quantity $M$ that represents the generalization of $\mathrm{r}$, a real number. Intuitively, $\mathrm{M}(\mathrm{x})$ should be a measure of how well $\mathrm{M}(\mathrm{x})$ approximates " $r$ ". The convex normalized fuzzy set is the fuzzy number $\mathrm{f}$. It characterized the given interval if real numbers, with a grade between 0 and 1 for each membership.

$$
\mu(x / M)=\left\{\begin{array}{l}
0, \quad x<l \\
\frac{x-a}{b-a} \text { a } x x \\
\frac{c-x}{c-b} \quad b \\
0, \quad x>u
\end{array}\right.
$$

Diverse fuzzy number can be used for different conditions. Generally in practice, triangular and trapezoidal fuzzy numbers are used . ${ }^{6}$ Typically; it is easier to work with triangular fuzzy numbers (TFNs) 
in applications because it is computationally simpler. Moreover, they are more useful when promoting the representation and information processing in a fuzzy environment ${ }^{48,49}$ Figure 8 shows the triangular fuzzy number, $\mathrm{M}$ :

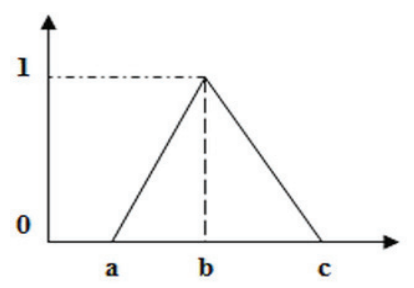

Fig. 8. A triangular fuzzy number, $\mathrm{M}$

Three real number, denoted by a, b and c, are defined in TFNs. These parameters respectively signify the smallest possible value, followed by the most promising value and finally the largest possible value that defines the fuzzy event. The function of the membership is described as earlier mentioned, we adopt fuzzy AHP method to evaluate the consensus of experts after content validity and selection of ten factors among twenty by experts. Hierarchical structure is required in FAHP.

Table 2. Triangular fuzzy conversion scale.

\begin{tabular}{lll}
\hline Row & Triangular & Triangular \\
\hline 1 & $(1,1,1)$ & $(1,1,1)$ \\
2 & $(1,3,5)$ & $(1 / 5,1 / 3,1)$ \\
3 & $(3,5,7)$ & $(1 / 7,1 / 5,1 / 3)$ \\
4 & $(5,7,9)$ & $(1 / 9,1 / 7,1 / 5)$ \\
5 & $(7,9,11)$ & $(1 / 11,1 / 9,1 / 7)$ \\
\hline
\end{tabular}

As a result of the outcome of content validity, ten factors selected in first run of content validity are $\mathrm{C} 1$ : Relative Advantage (RA), C2: Complexity Factor (CF) C3: Compatibility Factor (COF), under Technical dimension C4: Top Management Support(TM), C5: Policy and Standardization (PS), C6: Customization Factor (CUF), under organizational and C7: Security Factor (SF), C8: Outage and Monitoring (OM) under Technical-Organizational dimension and Trainer Partner Pressure (TPP), Competitor Pressure (CP) under Environmental dimension. Figure 9(appendix) depicts the hierarchical structure considered for this proposed system.$^{51}$

As mentioned before, to ensure the consensus of experts about validity factors in round one of content validity, a fuzzy questionnaire was designed and distributed among panel of experts via e-mail. The questionnaire designed according to the analytic hierarchy structure. The fuzzy questionnaire survey is applied to facilitate compare pairs of construct, in each level with respect to every construct in the next higher level. For each pair wise comparison, the respondents have been asked to determine the level of the relative importance between the two elements. In Saaty method, nine-point scale is recommended. ${ }^{55}$ However, taking into consideration the easy answering, this study only uses the five-point scale. The questionnaire showed in Figure 10. ${ }^{56,57}$

\section{RESULTS}

Based on four steps of this research, there are four results:

- The results of step 1 have been tabulated in Table 1.

- Step2: Calculation of the degree of possibility of each factor is done. For this purpose, each trilateral element is divided into three columns and the value of each component out of 1 calculated and put in a cell. Table 3 shows the result of this calculation.

- Step 3: The degree of possibility for a convex fuzzy number to be greater than $\mathrm{k}$ convex fuzzy 25 y number defined and showed in Table 4.

- Step 4: The normalized weight vectors are calculated via normalization, which gives a nonfuzzy number. Mathematical operations cannot be created directly using security evaluation values particularly the common attack values. However, it is rather best to convert the attack scale into a fuzzy scale. ${ }^{48}$ There is a variety of different fuzzy scales. The triangular fuzzy conversion scale in this paper (shown in table 5 below) is used in the evaluation model founded by Gumus (2009). ${ }^{48,50}$

After this the calculated fuzzy value that shows in Table 5, have normalized by using the following formula $\mathrm{V}(\mathrm{C} 1>\mathrm{c} 2)=1$ if $(\mathrm{Mc} 1>=\mathrm{Mc} 2), \mathrm{V}(\mathrm{C} 1>\mathrm{c} 2)=0$ if $(\mathrm{Lc} 2>=\mathrm{Uc} 1)$ otherwise the $\mathrm{v}$ have be calculate by using the following formula $\mathrm{V}$ : (lc2-Uc1)/ ((Mc1$\mathrm{Uc1}$ )-(Mc2-Lc2)). Then after minimum of each column have been calculated. This minimum is equal to weight of the factors. As you can see in table 6 the weight of factors are $\mathrm{C} 1=1.000, \mathrm{C} 2=0.250, \mathrm{C} 3=$ $0.245, \mathrm{C} 4=0.628, \mathrm{C} 5=0.056, \mathrm{C} 6=0.433, \mathrm{C} 7=0.188$, $\mathrm{C} 8=0.077, \mathrm{C} 9=0.000, \mathrm{c} 10=0.000$. This result showed that importance of factors are $\mathrm{C} 1=$ Relative Advantage $=1, \mathrm{C} 4=$ Top management support $=0.628$, C6Policy and Standardization $=0.433, \quad$ C2Complexity $=0.250$, $\mathrm{C} 3$ Compatibility $=\quad 0.245, \quad \mathrm{C} 7=\mathrm{Security}=0.188$, $\mathrm{C} 8=$ outage $=0.077, \mathrm{C} 5=$ Firm size $=0.056$. Moreover, 
two factors namely Competitor Pressure and Trainer partner Pressure have zero weight which means they are not significant in our model. So, environmental dimension will remove from the model completely.

\section{Conclusion}

Cloud computing will helps companies to reduce operating costs and increase the efficiency of operations. However, based on the current security problems, it seems more research in this area is required. Although some famous organizations like Google and IBM have deployed and use cloud computing as data center already, but adoption process of cloud computing data center is still contentious in some organizations. Therefore the main purpose of this paper was to find out Critical Success Factors for Adoption of Cloud Computing among organizations.

Thus this paper presents an overview of current data centers problems and cloud computing as alternative for current data centers, its benefits and classifications. We thereafter reviewed current cloud computing data center adoption models. Moreover, to extract new factors an interview with 10 administrator and IT staff is done. The adoption factors were identified and structured in a table. To find out the most relevant factors among the identified success factors, and recognize critical success factors, a content validity was carried out. In content validity via experts, some factors were chosen.

To evaluate the consensus of experts, the FAHP method was used. Finally, among twenty factors for adoption of cloud-based data center eight factors were accepted as critical success factors for adoption of CCDC. These factors are relative advantage, complexity, compatibility, top Management Support, customization, security, policy, and outage .After that, a conceptual model is going to propose based on CSF. Moreover for future work, evaluating the proposed model will be substantial.

\section{References}

1. O. Fatahi Valilai and M. Houshmand, A platform for optimisation in distributed manufacturing enterprises based on cloud manufacturing paradigm. International Journal of Computer Integrated Manufacturing, aheadof-print. 27(11) (2014), pp. 1-24.

2. R.L. Grossman, The case for cloud computing. IT professional. IEEE. 11(2) (2009), pp. 23-27.
3. Q. Zhang, L. Cheng, and R. Boutaba, Cloud computing: state-of-the-art and research challenges. Journal of internet services and applications (JISA). 1(1) (2010), pp. 7-18.

4. A. Aljabre, Cloud computing for increased business value. International Journal of Business and Social Science (IJBSS). 3(1) (2012), pp. 234-239.

5. R. Brown, Report to congress on server and data center energy efficiency: Public law. Lawrence Berkeley National Laboratory (2008), pp. 109-431.

6. M.F. Bari, et al., Data center network virtualization: A survey. Communications Surveys \& Tutorials, IEEE. 15(2) (2013), pp. 909-928.

7. N. Pereira, S. Tennina, and E. Tovar, Building a microscope for the data center, in Wireless Algorithms, Systems, and Applications (Springer, 2012), pp. 619630.

8. A. Marinos and G. Briscoe, Community cloud computing, in Cloud Computing. (Springer, 2009), pp. 472-484.

9. D. Jayasinghe, et al. Experts: A Generator Approach to Automate Performance Testing in IaaS Clouds. In Cloud Computing (CLOUD), 2012 IEEE 5th International Conference on (2012), pp. 115-122.

10. H. Qi and A. Gani. Research on mobile cloud computing: Review, trend and perspectives. in Digital Information and Communication Technology and it's Applications (DICTAP), 2012 Second International Conference on IEEE( 2012), pp. 195-202.

11. S. Lohr, Google and IBM join in 'cloud computing' research. 8(New York Times, 2007).

12. Y.-Y. Cheng and H.-J. Shaw, Cloud-based, serviceoriented and knowledge-sharing architecture: its design and application in shipbuilding. International Journal of Computer Integrated Manufacturing, ahead-of-print (2014), pp. 1-18.

13. W. He and L. Xu, A state-of-the-art survey of cloud manufacturing. International Journal of Computer Integrated Manufacturing 28(2) (2014), pp. 1-12.

14. W. Kim, et al. Adoption issues for cloud computing, in Proc. 7rd Int. Conf. on Advances in Mobile Computing and Multimedia (7)(ACM. 2009),pp. 2-5.

15. N.S.A.o. Ireland, Adopting the Cloud - decision support for cloud computing. The business perspective. Decision Support Systems, 51(1) (2012), pp.1-27.

16. I.R. Reports, Critical Link (2008).

17. M. Schwartz, Integrating Your Cloud and On-Premises Applications (2008), pp.1-12.

18. IBM, Defining a framework for cloud adoption (2010), pp.1-12.

19. Ali Khajeh-Hosseini, et al., The cloud adoption toolkit: supporting cloud adoption decisions in the enterprise. Software: Practice and Experience. 42(4) (2012), pp. 447-465. 
20. C. Low, Y. Chen, and M. Wu, Understanding the determinants of cloud computing adoption. Industrial Management \& Data Systems. 111(7) (2011), pp. 10061023.

21. E. Rogers, Diffusion of innovations (New York, 1983), pp. 313-330.

22. M.L. To and E.W. Ngai, Predicting the organisational adoption of B2C e-commerce: an empirical study. Industrial Management \& Data Systems. 106(8) (2006), pp. 1133-1147.

23. T. Oliveira and M.F. Martins, Understanding e-business adoption across industries in European countries. Industrial Management \& Data Systems. 110(9) (2010), pp. 1337-1354.

24. K. Zhu, et al., Innovation diffusion in global contexts: determinants of post-adoption digital transformation of European companies. European Journal of Information Systems. 15(6) (2006), pp. 601-616.

25. P.Y. Chau and K.L. Hui, Determinants of small business EDI adoption: an empirical investigation. Journal of Organizational Computing and Electronic Commerce. 11(4) (2001), pp. 229-252.

26. M.-J. Pan and W.-Y. Jang, Determinants of the adoption of enterprise resource planning within the technology-organization-environment framework: taiwan's communications industry. Journal of Computer Information Systems. 48(3) (2008), p. 94.

27. B. Dehning and V.J. Richardson, Returns on investments in information technology: A research synthesis. Journal of Information Systems. 16(1) (2002), pp. 7-30.

28. I. Son and D. Lee, Assessing a new IT service model, cloud computing. PACIS 2011 Proceedings. (2011), p. 179

29. R.G. Fichman, Going beyond the dominant paradigm for information technology innovation research: Emerging concepts and methods. Journal of Computer Information Systems 5(8) (2004), pp. 314-355.

30. P.Y. Chau and K.Y. Tam, Factors affecting the adoption of open systems: an exploratory study. Mis Quarterly, (1997), pp. 1-24.

31. B. Kogut and U. Zander, Knowledge of the firm and the evolutionary theory of the multinational corporation. Journal of international business studies, 34(6), pp. 516-529.

32. A.S. Bharadwaj, A resource-based perspective on information technology capability and firm performance: an empirical investigation. Mis Quarterly, (2000), p p. 169-196.

33. L.G. Tornatzky, M. Fleischer, and A.K. Chakrabarti, The processes of technological innovation. 273 (Lexington Books Lexington, MA, 1990), pp. 45-46.

34. S. Bikhchandani, D. Hirshleifer, and I. Welch, A theory of fads, fashion, custom, and cultural change as informational cascades. Journal of political Economy, 100(5) (1992), pp. 992-1026.
35. G. Feuerlicht and N. Margaris. "Cloud Computing Adoption: A comparative study." Proceedings of the 1st WSEAS International Conference on Cloud Computing (CLC'12), Vienna, Austria. Recent Advances in Computer Engineering Series (WSEAS. 2012), PP.1-8.

36. N. Badie, A.R.C. Hussin, and E. Yadegaridehkordi, The Policy as Repudiation Factors of Adopting Cloud Computing in University Administration, Journal of information systems research and innovation. 3(1) (2013), pp. 54-63.

37. B. Adam, Enterprise cloud adoption framework standardization as the road to enterprise cloud. (2012).

38. M. Mircea and A.I. Andreescu, Using Cloud Computing in Higher Education: A Strategy to Improve Agility in the Current Financial Crisis. Communications of the IBIMA (2011), pp.1-15.

39. W. Suen, A correlation inequality and a Poisson limit theorem for non overlapping balanced subgraphs of a random graph. Random Structures \& Algorithms. 1(2) (1990), pp. 231-242.

40. J.C. Nunnally and I.H. Bernstein, Psychometric theory. 1994. McGraw, New York, (1991).

41. S.Messick,. Validity of psychological assessment: validation of inferences from persons' responses and performances as scientific inquiry into score meaning. American psychologist. 50(9) (1995), p.741.

42. S.N. Haynes, D. Richard, and E.S. Kubany, Content validity in psychological assessment: A functional approach to concepts and methods. Psychological assessment. 7(3) (1995), pp. 238.

43. A. Anastasi and S. Urbina, Psychological testing (Prentice Hall Upper Saddle River, NJ, 1997).

44. A.E.R. Association, et al., Standards for educational and psychological testing (Amer Educational Research Assn, 1999.

45. R. Sartori and M. Pasini, Quality and Quantity in Test Validity: How can we be sure that Psychological Tests Measure what they have to? Quality \& quantity. 41(3) (2007), pp. 359-374.

46. R. Sartori, Face validity in personality tests: psychometric instruments and projective techniques in comparison. Quality \& quantity. 44(4) (2010), pp. 749759.

47. M. Ekmekçioğlu and A. Can Kutlu, A Fuzzy Hybrid Approach for Fuzzy Process FMEA: An Application to a Spindle Manufacturing Process, International Journal of Computational Intelligence Systems (ijcis). 5(4) (2012), pp. 611-626.

48. A.H. Lashkari, A.A. Manaf, and M. Masrom. Graphical Password Security Evaluation by Fuzzy AHP, world academy of science, Engineering and technology, 6(6)( WASET, 2012), 267-272.

49. G. Büyüközkan, C. Kahraman, and D. Ruan, A fuzzy multi-criteria decision approach for software development strategy selection. International Journal of General Systems. 33(2-3) (2004), pp. 259-280. 
50. A.T. Gumus, Evaluation of hazardous waste transportation firms by using a two step fuzzy-AHP and TOPSIS methodology, Expert Systems with Applications. 36(2) (2009), pp. 4067-4074.

51. A.T. Gumus, Evaluation of hazardous waste transportation firms by using a two step fuzzy-AHP and TOPSIS methodology, Expert Systems with Applications. 36(2) (2009), pp. 4067-4074.

52. Flynn, B.B., et al., Empirical research methods in operations management. Journal of Operations Management, 9(2) (1990), pp. 250-284.

53. Lawshe, C.H., A quantitative approach to content validity1. Personnel psychology.28 (4) (1975), pp. 563 575.

54. F. Robert Wilson, W. P., and Donald A. Schumsky Measurement and Evaluation in Counseling and Development .2(4) (2012), pp. 296-307.

55. Saaty, T.L., How to make a decision: the analytic hierarchy process, European journal of operational research. 48(1) (1990), pp. 9-26.

56. Yang, C.-C. and B.-S. Chen, Key quality performance evaluation using fuzzy AHP, Journal of the Chinese Institute of Industrial Engineers. 21(6)( 2004), pp. 543550.

57. Yang, J. L., H. N. Chiu, et al. "Vendor selection by integrated fuzzy MCDM techniques with independent and interdependent relationships", Information Sciences. 178(21) (2008), pp.4166-4183.

58. Wyld, D.C., the Cloudy future of government IT: Cloud computing and the public sector around the world, International Journal of Web \& Semantic Technology, 1(1) (2010), pp. 1-20.

59. Lee, G. and W. Xia. "Organizational size and IT innovation adoption: A meta-analysis.", Information \& Management, 43(8) (2006),pp. 975-985.

60. Delmar, F., P. Davidsson, and W.B. Gartner, Arriving at the high-growth firm, Journal of Business Venturing. 18(2)( 2003), pp. 189-216.

61. Wagner, J., Exports and productivity: A survey of the evidence from firm level data. The World Economy, 2007. 30(1), pp. 60-82.

62. Bibi, S., D. Katsaros, and P. Bozanis, Business application acquisition: on-premise or SaaS-based solutions? Software, IEEE. 29(3) (2012), pp. 86-93.

63. Wang, H., W. He, and F.-K. Wang, Enterprise cloud service architectures. Information Technology and Management, 13(4) (2012), pp. 445-454.

64. Dholakia, R. R. and N. Kshetri, Factors impacting the adoption of the Internet among SMEs, Small Business Economics. 23(4) (2004), pp. 311-322. 


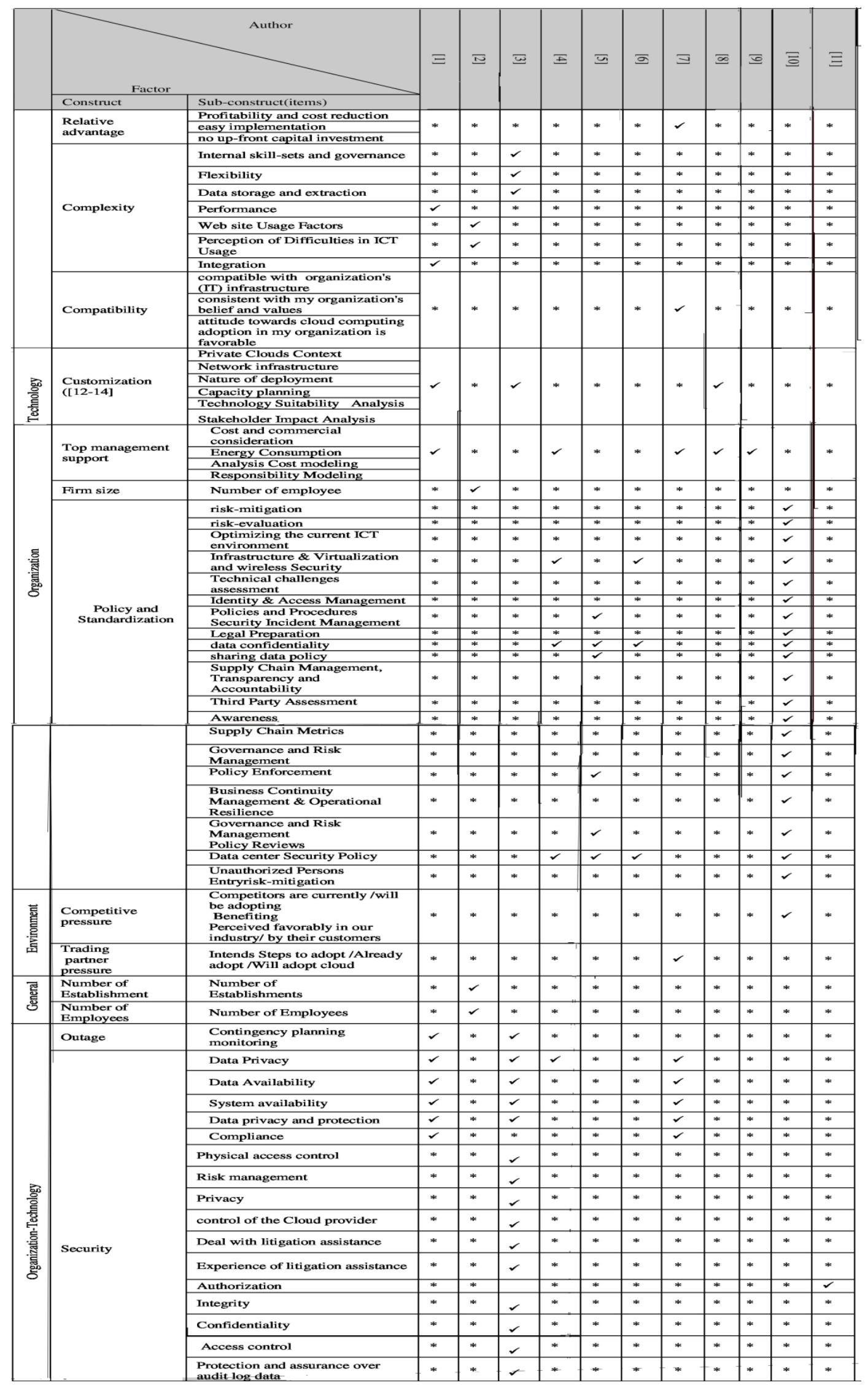

Fig.6 Success Factors for Adoption of Cloud Computing Cospublished by Atlantis Press and Taylor \& Francis Copyright: the authors 


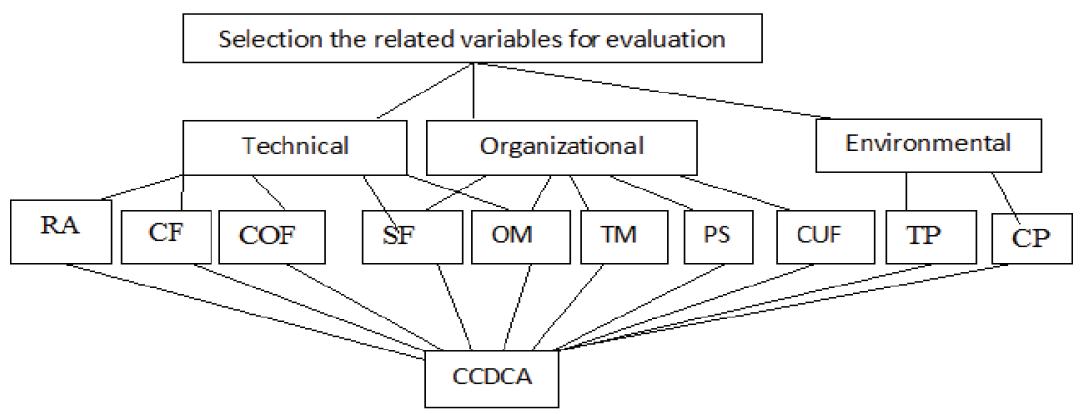

Fig.9. The hierarchy to CSF evaluation of cloud base data center adoption

\begin{tabular}{|c|c|c|c|c|c|c|c|}
\hline \multirow{2}{*}{$Q$} & \multirow{2}{*}{ Attribute } & \multicolumn{5}{|c|}{ Furzy Scale } & \multirow{2}{*}{ Attribute } \\
\hline & & 1 & 2 & 3 & 4 & 5 & \\
\hline Q1 & \multirow{9}{*}{ Relative Advantage (RA) } & & & & & & Complexity Factor (CF) \\
\hline$Q 2$ & & & & & & & Compatibility Factor (COF) \\
\hline Q3 & & & & & & & Top Management Support (TMS) \\
\hline Q4 & & & & & & & Policy and Standardization (PS) \\
\hline Q5 & & & & & & & Customization Factor (CUF) \\
\hline Q6 & & & & & & & Security Factor (SF) \\
\hline Q7 & & & & & & & Outage and Monitoring (OM) \\
\hline$Q 8$ & & & & & & & Trading Partner presaure (TPP) \\
\hline$Q 9$ & & & & & & & Competitor Pressure (CP) \\
\hline Q10 & \multirow{8}{*}{ Complexity Factor (CF) } & & & & & & Compatibility Factor (COF) \\
\hline Q11 & & & & & & & Top Management Support (TMS) \\
\hline Q12 & & & & & & & Policy and Standardization (PS) \\
\hline Q13 & & & & & & & Customization Factor (CUF) \\
\hline Q14 & & & & & & & Security Factor (SF) \\
\hline Q15 & & & & & & & Outage and Monitoring (OM) \\
\hline Q16 & & & & & & & Trading Partner pressure (TPP) \\
\hline Q17 & & & & & & & Competitor Pressure (CP) \\
\hline Q18 & \multirow{7}{*}{ Compatibility Factor (COF) } & & & & & & Top Management Support (TMS) \\
\hline Q19 & & & & & & & Policy and Standardization (PS) \\
\hline Q20 & & & & & & & Customization Factor (CUF) \\
\hline Q21 & & & & & & & Security Factor (SF) \\
\hline$Q 22$ & & & & & & & Outage and Monitoring (OM) \\
\hline Q23 & & & & & & & Trading Partner pressure (TPP) \\
\hline Q24 & & & & & & & Competitor Pressure (CP) \\
\hline Q25 & \multirow{6}{*}{$\begin{array}{l}\text { Top Management Support } \\
\text { (TMS) }\end{array}$} & & & & & & Policy and Standardization (PS) \\
\hline Q26 & & & & & & & Customization Factor (CUF) \\
\hline$Q 27$ & & & & & & & Security Factor (SF) \\
\hline Q28 & & & & & & & Outage and Monitoring (OM) \\
\hline Q29 & & & & & & & Trading Partner pressure (TPP) \\
\hline Q30 & & & & & & & Competitor Pressure (CP) \\
\hline Q31 & \multirow{5}{*}{$\begin{array}{l}\text { Policy and Standardization } \\
\text { (PS) }\end{array}$} & & & & & & Customization Factor (CUF) \\
\hline Q32 & & & & & & & Security Factor (SF) \\
\hline Q33 & & & & & & & Outage and Monitoring (OM) \\
\hline Q34 & & & & & & & Trading Partner pressure (TPP) \\
\hline Q35 & & & & & & & Competitor Pressure (CP) \\
\hline Q36 & \multirow{4}{*}{ Customization Factor (CUF) } & & & & & & Security Factor (SF) \\
\hline Q37 & & & & & & & Outage and Monitoring (OM) \\
\hline Q38 & & & & & & & Trading Partner pressure (TPP) \\
\hline Q39 & & & & & & & Competitor Pressure (CP) \\
\hline$Q 40$ & \multirow{3}{*}{ Security Factor (SF) } & & & & & & Outage and Monitoring (OM) \\
\hline Q41 & & & & & & & Trading Partner pressure (TPP) \\
\hline Q42 & & & & & & & Competitor Pressure (CP) \\
\hline Q43 & \multirow{2}{*}{ Outage and Monitoring (OM) } & & & & & & Trading Partner pressure (TPP) \\
\hline$Q 44$ & & & & & & & Competitor Pressure (CP) \\
\hline Q45 & $\begin{array}{l}\text { Trading Partner pressure } \\
\text { (TPP) }\end{array}$ & & & & & & Competitor Pressure (CP) \\
\hline
\end{tabular}

Fig. 10. Questionnaire

Co-published by Atlantis Press and Taylor \& Francis

Copyright: the authors

868 
Table 1. Content Validity Result.

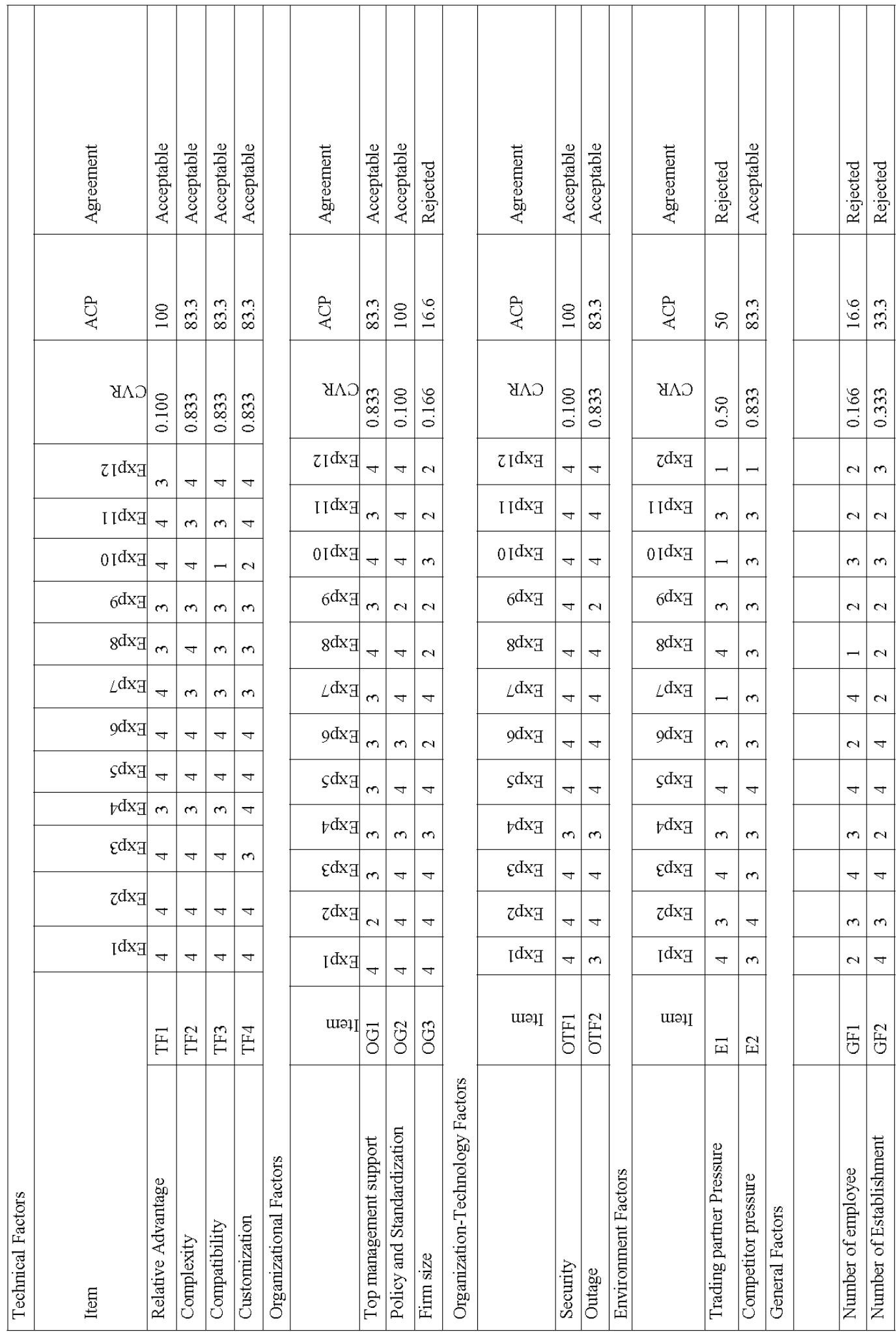

ACP: Acceptance Percentage 
Table 3.. Result of expert consensuses in step 1.

\begin{tabular}{|c|c|c|c|c|c|c|c|c|c|c|}
\hline$\stackrel{\circ}{0}$ & $\begin{array}{l}\hat{=} \\
\hat{\sigma}\end{array}$ & 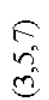 & 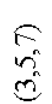 & $\begin{array}{l}\text { हn } \\
\hat{a}^{2}\end{array}$ & $\begin{array}{l}\hat{\Xi} \\
\hat{2}\end{array}$ & $\begin{array}{l}\hat{2} \\
\stackrel{m}{=}\end{array}$ & $\begin{array}{l}E \\
n^{n}\end{array}$ & $\begin{array}{l}\text { 三 } \\
\text { हn } \\
\text { है }\end{array}$ & $\begin{array}{l}\stackrel{\Xi}{a} \\
\vec{a}\end{array}$ & $\Rightarrow$ \\
\hline 8 & $\begin{array}{l}\hat{n} \\
\cdots \\
\cdots\end{array}$ & $\begin{array}{l}\text { हn } \\
\hat{a}^{2}\end{array}$ & $\begin{array}{l}\text { En } \\
\text { ch }\end{array}$ & $\begin{array}{l}\text { हn } \\
\text { ma }\end{array}$ & $\begin{array}{l}E \\
n \\
n \\
c\end{array}$ & 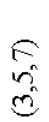 & $\begin{array}{l}\text { En } \\
\tilde{c}^{0}\end{array}$ & $\begin{array}{l}\text { 三 } \\
\text { हn }\end{array}$ & $\begin{array}{l}\exists \\
\approx\end{array}$ & $\begin{array}{l}\vec{n} \\
\vec{n} \\
\vec{E}\end{array}$ \\
\hline$\infty$ & $\begin{array}{l}\hat{2} \\
\hat{b}\end{array}$ & $\begin{array}{c}\text { हn } \\
\text { ma }\end{array}$ & $\begin{array}{l}E \mathbf{n} \\
\tilde{c}^{0}\end{array}$ & $\begin{array}{c}E \\
\hat{n} \\
\hat{0}\end{array}$ & $\begin{array}{l}2 \\
\hat{b} \\
b\end{array}$ & $\begin{array}{l}\hat{\partial} \\
\hat{n}\end{array}$ & $\begin{array}{l}E \\
\tilde{a}^{0} \\
\hat{a}^{2}\end{array}$ & $\begin{array}{l}\Rightarrow \\
\Rightarrow\end{array}$ & 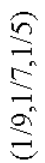 & 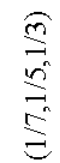 \\
\hline $\bar{v}$ & $\begin{array}{l}\hat{E} \\
\hat{m}\end{array}$ & $\begin{array}{l}\text { हn } \\
\text { m }\end{array}$ & $\begin{array}{l}\text { En } \\
\text { [n } \\
\text { [n }\end{array}$ & $\begin{array}{l}2 \\
\hat{\approx} \\
\hat{n}\end{array}$ & $\begin{array}{l}2 \\
\hat{2} \\
b\end{array}$ & $\begin{array}{l}E \hat{n} \\
\text { ली }\end{array}$ & $\Rightarrow$ & 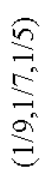 & 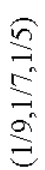 & $\begin{array}{l}\widehat{a} \\
= \\
气 \\
a \\
\vdots\end{array}$ \\
\hline 8 & $\begin{array}{l}\hat{a} \\
\hat{b}\end{array}$ & $\begin{array}{l}\hat{2} \\
\ddot{\approx}\end{array}$ & $\begin{array}{l}\text { हn } \\
\text { m }\end{array}$ & $\begin{array}{l}\hat{2} \\
\hat{\approx}\end{array}$ & $\begin{array}{l}\hat{n} \\
\hat{n} \\
\hat{c}\end{array}$ & $\Rightarrow$ & 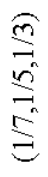 & 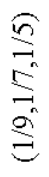 & 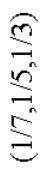 & $\begin{array}{l}\stackrel{\text { m}}{\Xi} \\
\stackrel{n}{\Xi}\end{array}$ \\
\hline 3 & $\begin{array}{l}\hat{2} \\
\hat{n}\end{array}$ & $\begin{array}{l}\text { हn } \\
\text { ñ }\end{array}$ & $\begin{array}{l}\text { हे } \\
\hat{n}\end{array}$ & $\begin{array}{l}\text { En } \\
\text { nी } \\
\text { ली }\end{array}$ & $\Rightarrow$ & $\begin{array}{l}\stackrel{m}{=} \\
n \\
= \\
\underline{\Xi}\end{array}$ & 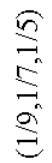 & 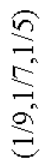 & 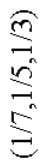 & 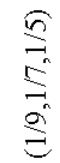 \\
\hline ঠ & $\begin{array}{l}\hat{a} \\
\hat{a}\end{array}$ & $\begin{array}{l}\text { हn } \\
\text { ली }\end{array}$ & $\begin{array}{l}\hat{2} \\
\hat{a}\end{array}$ & $\Rightarrow$ & 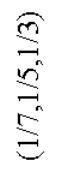 & 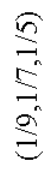 & 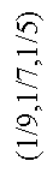 & 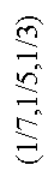 & \begin{tabular}{l}
$\underset{m}{=}$ \\
\multirow{n}{=}{} \\
$\stackrel{n}{\Xi}$
\end{tabular} & 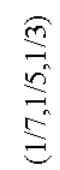 \\
\hline 3 & $\begin{array}{l}\hat{2} \\
\hat{b}\end{array}$ & $\begin{array}{l}\text { हn } \\
\text { an }\end{array}$ & 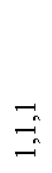 & $\begin{array}{l}\hat{\Omega} \\
= \\
= \\
\stackrel{5}{E}\end{array}$ & 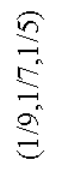 & \begin{tabular}{l}
$\underset{m}{=}$ \\
\multirow{n}{n}{} \\
$\underline{\Xi}$ \\
$\Xi$
\end{tabular} & 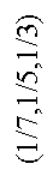 & 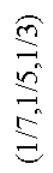 & 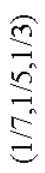 & 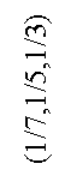 \\
\hline$\widetilde{U}$ & $\begin{array}{l}\vec{a} \\
\vec{b}\end{array}$ & $\exists$ & 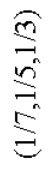 & 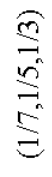 & 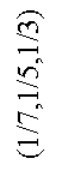 & $\begin{array}{l}\hat{n} \\
= \\
\stackrel{n}{=} \\
a^{n} \\
\Xi\end{array}$ & $\begin{array}{l}\stackrel{m}{=} \\
\stackrel{n}{=} \\
\stackrel{=}{E}\end{array}$ & $\begin{array}{l}\stackrel{m}{\Rightarrow} \\
\stackrel{n}{=} \\
\underline{\varepsilon} \\
\Xi\end{array}$ & 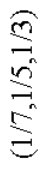 & $\begin{array}{l}\cong \\
n \\
n \\
\Xi \\
\Xi\end{array}$ \\
\hline$\vec{U}$ & $\Rightarrow$ & 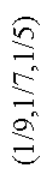 & 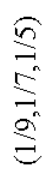 & 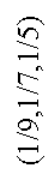 & 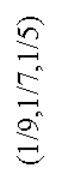 & 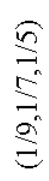 & $\begin{array}{l}\stackrel{m}{=} \\
\stackrel{n}{=} \\
\stackrel{5}{\Xi}\end{array}$ & $\begin{array}{l}\hat{\Omega} \\
= \\
\stackrel{5}{=} \\
\stackrel{2}{\varepsilon}\end{array}$ & $\begin{array}{l}\underset{m}{=} \\
\stackrel{n}{=} \\
\stackrel{n}{\Xi}\end{array}$ & 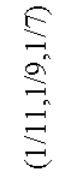 \\
\hline 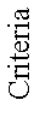 & $\vec{u}$ & $\widetilde{U}$ & $c$ & $J$ & 3 & ن & 0 & P & 8 & $\vec{u}$ \\
\hline
\end{tabular}


Table 4. Degree of possibility of each factor.

\begin{tabular}{|c|c|c|c|c|c|c|c|c|c|c|c|}
\hline sum & $\mathrm{C} 10$ & C9 & C8 & C7 & C6 & C5 & $\mathrm{C} 4$ & C3 & $\mathrm{C} 2$ & $\mathrm{C} 1$ & \\
\hline 2.03 & 0.09 & 0.14 & 0.11 & 0.14 & 0.11 & 0.11 & 0.11 & 0.11 & 0.11 & 1.00 & C.1 \\
\hline 2.35 & 0.11 & 0.20 & 0.14 & 0.20 & 0.14 & 0.14 & 0.14 & 0.14 & 0.14 & 1.00 & C1 \\
\hline 3.00 & 0.14 & 0.33 & 0.20 & 0.33 & 0.20 & 0.20 & 0.20 & 0.20 & 0.20 & 1.00 & $\mathrm{C} 1$ \\
\hline 7.09 & 0.14 & 0.14 & 0.14 & 0.14 & 0.11 & 0.14 & 0.14 & 0.14 & 1.00 & 5.00 & $\mathrm{C} 2$ \\
\hline 9.54 & 0.20 & 0.20 & 0.20 & 0.20 & 0.14 & 0.20 & 0.20 & 0.20 & 1.00 & 7.00 & $\mathrm{C} 2$ \\
\hline 12.51 & 0.33 & 0.33 & 0.33 & 0.33 & 0.20 & 0.33 & 0.33 & 0.33 & 1.00 & 9.00 & $\mathrm{C} 2$ \\
\hline 9.92 & 0.14 & 0.14 & 0.14 & 0.14 & 0.14 & 0.11 & 0.11 & 1.00 & 3.00 & 5.00 & C3 \\
\hline 14.28 & 0.20 & 0.20 & 0.20 & 0.20 & 0.20 & 0.14 & 0.14 & 1.00 & 5.00 & 7.00 & C3 \\
\hline 19.05 & 0.33 & 0.33 & 0.33 & 0.33 & 0.33 & 0.20 & 0.20 & 1.00 & 7.00 & 9.00 & C3 \\
\hline 14.78 & 0.14 & 0.14 & 0.14 & 0.11 & 0.11 & 0.14 & 1.00 & 5.00 & 3.00 & 5.00 & $\mathrm{C} 4$ \\
\hline 21.08 & 0.20 & 0.20 & 0.20 & 0.14 & 0.14 & 0.20 & 1.00 & 7.00 & 5.00 & 7.00 & C4 \\
\hline 27.72 & 0.33 & 0.33 & 0.33 & 0.20 & 0.20 & 0.33 & 1.00 & 9.00 & 7.00 & 9.00 & $\mathrm{C} 4$ \\
\hline 17.61 & 0.11 & 0.14 & 0.11 & 0.11 & 0.14 & 1.00 & 3.00 & 5.00 & 3.00 & 5.00 & C5 \\
\hline 25.82 & 0.14 & 0.20 & 0.14 & 0.14 & 0.20 & 1.00 & 5.00 & 7.00 & 5.00 & 7.00 & C5 \\
\hline 34.26 & 0.20 & 0.33 & 0.20 & 0.20 & 0.33 & 1.00 & 7.00 & 9.00 & 7.00 & 9.00 & C5 \\
\hline 22.59 & 0.20 & 0.14 & 0.11 & 0.14 & 1.00 & 3.00 & 5.00 & 3.00 & 5.00 & 5.00 & C6 \\
\hline 32.87 & 0.33 & 0.20 & 0.14 & 0.20 & 1.00 & 5.00 & 7.00 & 5.00 & 7.00 & 7.00 & C6 \\
\hline 43.86 & 1.00 & 0.33 & 0.20 & 0.33 & 1.00 & 7.00 & 9.00 & 7.00 & 9.00 & 9.00 & C6 \\
\hline 23.39 & 0.11 & 0.14 & 0.14 & 1.00 & 3.00 & 5.00 & 5.00 & 3.00 & 3.00 & 3.00 & C7 \\
\hline 35.54 & 0.14 & 0.20 & 0.20 & 1.00 & 5.00 & 7.00 & 7.00 & 5.00 & 5.00 & 5.00 & C7 \\
\hline 47.86 & 0.20 & 0.33 & 0.33 & 1.00 & 7.00 & 9.00 & 9.00 & 7.00 & 7.00 & 7.00 & C7 \\
\hline 28.28 & 0.14 & 0.14 & 1.00 & 3.00 & 5.00 & 5.00 & 3.00 & 3.00 & 3.00 & 5.00 & $\mathrm{C} 8$ \\
\hline 42.40 & 0.20 & 0.20 & 1.00 & 5.00 & 7.00 & 7.00 & 5.00 & 5.00 & 5.00 & 7.00 & $\mathrm{C} 8$ \\
\hline 56.66 & 0.33 & 0.33 & 1.00 & 7.00 & 9.00 & 9.00 & 7.00 & 7.00 & 7.00 & 9.00 & $\mathrm{C} 8$ \\
\hline 29.14 & 0.14 & 1.00 & 7.00 & 3.00 & 3.00 & 3.00 & 3.00 & 3.00 & 3.00 & 3.00 & c9 \\
\hline 45.20 & 0.20 & 1.00 & 9.00 & 5.00 & 5.00 & 5.00 & 5.00 & 5.00 & 5.00 & 5.00 & c9 \\
\hline 61.33 & 0.33 & 1.00 & 11.00 & 7.00 & 7.00 & 7.00 & 7.00 & 7.00 & 7.00 & 7.00 & c9 \\
\hline 42.00 & 1.00 & 7.00 & 7.00 & 3.00 & 1.00 & 7.00 & 3.00 & 3.00 & 3.00 & 7.00 & $\mathrm{c} 10$ \\
\hline 60.00 & 1.00 & 9.00 & 9.00 & 5.00 & 3.00 & 9.00 & 5.00 & 5.00 & 5.00 & 9.00 & $\mathrm{cl0}$ \\
\hline 78.00 & 1.00 & 11.00 & 11.00 & 7.00 & 5.00 & 11.00 & 7.00 & 7.00 & 7.00 & 11.00 & $\mathrm{c} 10$ \\
\hline
\end{tabular}


Table 5. Possibility for a convex fuzzy number.

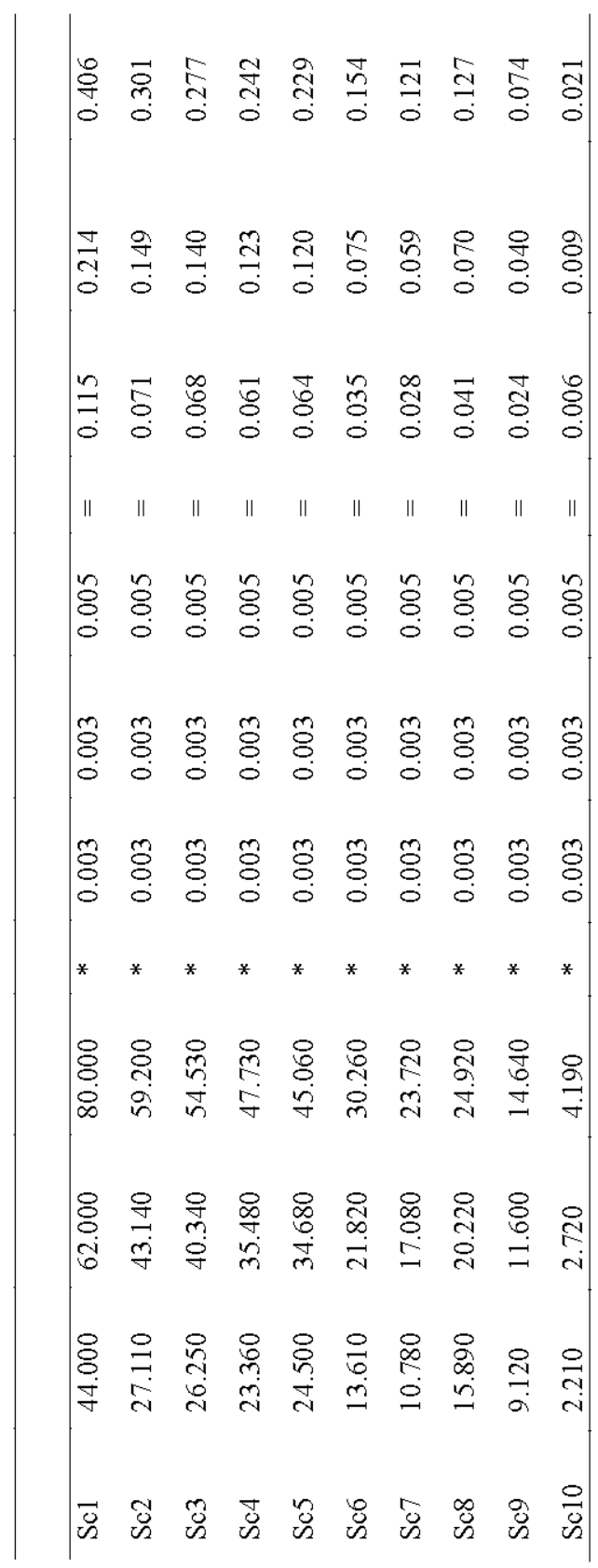


Table 6. Normalization.

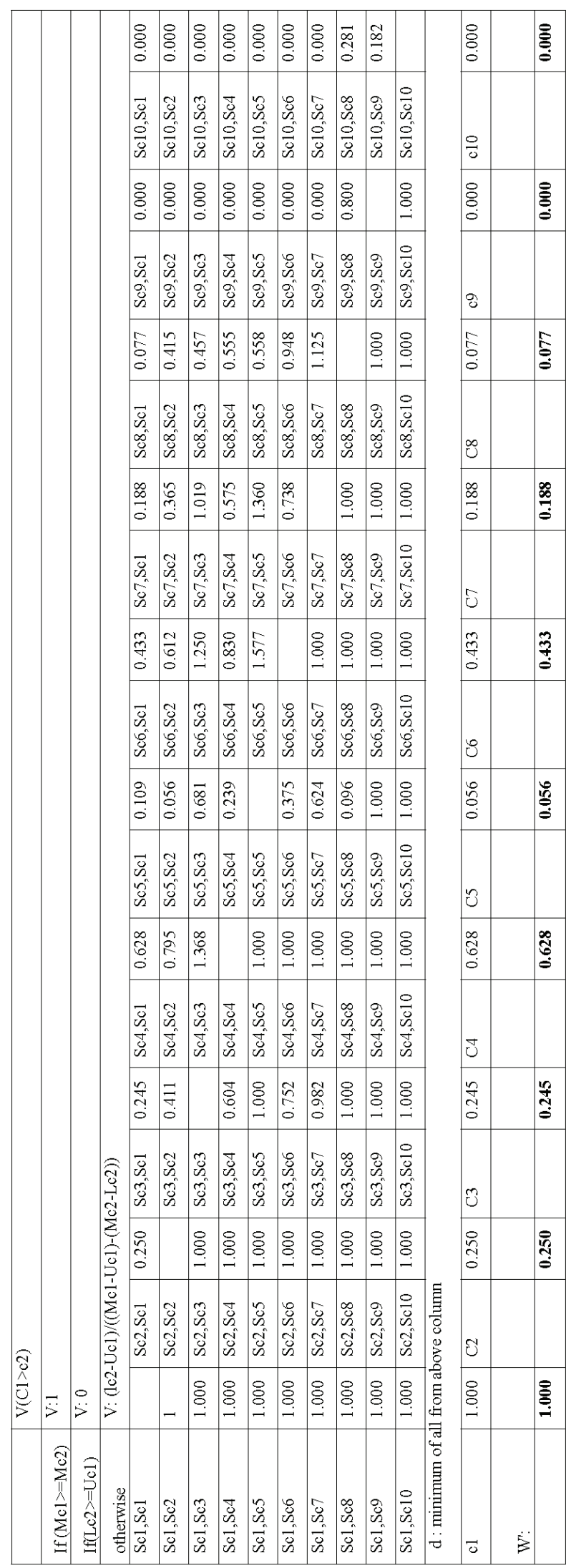

Co-published by Atlantis Press and Taylor \& Francis Copyright: the authors 